\title{
BERMAIN SEPEDA UNTUK MELATIH KEMAMPUAN MOTORIK KASAR ANAK USIA 5-6 TAHUN
}

\author{
Mahkamah Brantasari \\ PG PAUD Universitas Widya Gama Mahakam Samarinda \\ brantasari@gmail.com
}

\begin{abstract}
Playing A Bike To Train The Rude Motor Ability Of Children Age 5-6 Years Old. During the Covid-19 pandemic, children with active characteristics will of course feel bored with games in the house that are less free. And children feel limited in exploring physical activities related to gross motor skills. Children at an early age are very important to carry out physical movements with the aim of stimulating the physical growth of children's motor skills, both fine and gross motor skills. To make children excited about doing physical activities, one of them is by inviting them to ride bikes together. In a joint cycling situation, direct observations can be made and also ask what children feel when playing a bicycle, the research conducted by the author uses a case study of a child aged 5-6 years who plays a two-wheeled bicycle with a focus on training the child's gross motor skills. namely by locomotor, non-locomotor, and manipulative movements. From what has been done during the activity of playing bicycles, all of the movements made by children when playing bicycles have all referred to the gross motor skills of children, especially children aged 5-6 years.
\end{abstract}

Keywords: playing bicycles, gross motor skills of children 5-6 years

\begin{abstract}
Abstrak
Bermain Sepeda Untuk Melatih Kemampuan Motorik Kasar Anak Usia 5-6 Tahun. Selama pandemi covid-19, anak dengan karakteristiknya yang aktif tentu saja akan merasa jenuh dengan permainan di dalam rumah yang di rasa kurang bebas. Dan anak merasa terbatasi dalam mengeksplorasi kegiatan fisik yang berhubungan dengan motorik kasar. Anak pada usia dini sangat penting untuk melakukan gerakan fisik dengan tujuan untuk merangsang pertumbuhan fisik motorik anak, baik motorik halus maupun motorik kasar. Untuk membuat anak bersemangat melakukan kegiatan fisik salah satunya adalah dengan mengajak anak bersepeda bersama. Dalam situasi bersepeda bersama dapat dilakukan pengamatan secara langsung dan juga menanyakan hal-hal yang dirasakan anak ketika bermain sepeda, penelitian yang dilakukan oleh penulis menggunakan studi kasus pada seorang anak usia 5-6 tahun yang bermain sepeda roda dua dengan fokus pada melatih motorik kasar anak, yaitu dengan gerakan lokomotor, non lokomotor, serta gerakan manipulatif. Dari apa yang telah dilakukan pada saat aktivitas bermain sepeda maka semua gerakan-gerakan yang dilakukan anak pada saat bermain sepeda, semuanya telah mengacu pada kemampuan motorik kasar anak, terutama anak usia 5-6 tahun.
\end{abstract}

Kata kunci: bermain sepeda, motorik kasar anak 5-6 tahun

\section{PENDAHULUAN}

Masa Pandemi Covid-19 yang terjadi saat ini sangat berpengaruh terhadap kebiasaan bermain anak, karena yang biasanya anak akan lebih banyak menggunakan waktunya untuk bermain di luar rumah maka pada masa pandemi, anak terpaksa melakukan aktivitasnya di dalam rumah. Anak dengan karakteristiknya yang aktif tentu saja akan merasa jenuh dengan permainan di dalam rumah yang di rasa kurang bebas. Dan anak merasa terbatasi dalam mengeksplorasi kegiatan fisik yang berhubungan dengan motorik kasar.

Beberapa waktu belakangan ini permainan fisik banyak yang terkalahkan dengan permainan game yang ada pada aplikasi yang terdapat pada smartphone maupun leptop yang disebabkan kemajuan teknologi, menyebabkan anak menikmati bermain game yaitu permainan secara virtual yang sangat menyenangkan untuk dilakukan dan dimainkan baik secara perorangan maupun berkelompok.

Anak pada usia dini sangat penting untuk melakukan gerakan fisik dengan tujuan untuk merangsang pertumbuhan fisik motorik anak, baik motorik halus maupun kasar. Pada masa Pandemi Covid-19 dimana semua orang, baik orang dewasa hingga anak-anak dianjurkan untuk tidak berkegiatan di luar rumah, maka cenderung membuat orang melakukan kegiatan yang bersifat pasif. Sementara kegiatan fisik yang bersifat motorik kasar menjadi jarang untuk dilakukan. Pada keadaan sesungguhnya permainan secara fisik sendiri tentu sangat 
berbeda, karena permainan secara fisik akan melibatkan seluruh anggota tubuh baik motorik kasar dan juga motorik halus, sementara permainan game aplikatif tidak menggerakan fisik yang berakibat anak menjadi pasif dalam menggerakkan anggota tubuh mereka. karenanya itu bagi orang dewasa yang memiliki anak sebaiknya mengajak anak mereka untuk melakukan permainan yang melibatkan pergerakan seluruh anggota tubuh seperti bermain sepeda yang kegiatannya dapat dilakukan sekitar tempat tinggal, misalnya pada halaman rumah saja.

Agar bermain sepeda menjadi tambah menyenangkan, rencanakan bermain sepeda supaya menjadi lebih menarik. Untuk membuat anak bersemangat melakukan kegiatan fisik salah satunya adalah dengan mengajak anak bersepeda bersama. Dalam situasi bersepeda bersama dapat dilakukan pengamatan secara langsung dan juga menanyakan hal-hal yang dirasakan anak ketika bermain sepeda. Dalam artikel (Hasanah, 2016) menurut (Moeslichatoen, 2006:27) Dunia anak adalah dunia bermain, pada saat anak bermain mereka akan menyerap segala sesuatu yang terjadi di lingkungan sekitarnya, karena bermain merupakan tuntutan dan kebutuhan yang mendasar bagi anak usia dini, dengan bermain anak akan dapat memuaskan tuntutan dan kebutuhan perkembangan dimensi dari motorik, kognitif, bahasa, kreativitas, sosial, emosional, nilai, dan sikap hidup. Memahami dan mengerti tentang anak merupakan awal keberhasilan dalam pendidikan.

Bermain sepeda akan dialami oleh semua anak yang menyukai kegiatan tantangan. Bermain sepeda sendiri merupakan permainan yang sangat di gemari anak karena merupakan permainan yang sangat menyenangkan. Bersepeda merupakan salah satu permainan yang banyak mengeluarkan energi sehingga dapat menyalurkan energi anak yang berlebih. Anak pada usia 5-6 tahun sangat agresif dan banyak mengeluarkan tenaga dalam permainannya sehingga sangat di perlukan permainan yang aktif dalam menggerakan anggota tubuh anak.

Pada artikel (Sutini, 2018) Menurut Wong (1990) dan Foster (1984) pengertian bermain adalah suatu kegiatan yang dilakukan secara alamiah yang dilakukan anak atas inisiatif mereka sendiri dalam rangka mengeksplorasi kemampuan dirinya yang tidak disadari untuk memperoleh kesenangan dan kepuasan. Menurut beberapa pengertian, aktivitas bermain tidak sama dengan aktivitas lainnya seperti belajar, mandi, makan dan tidur. Namun dalam bermain sebenarnya anak sedang belajar. Perbedaan antara bermain dengan belajar, diantaranya adalah: 1). Kegiatan bermain menimbulkan rasa senang dan gembira pada anak. 2). Bermain merupakan kegiatan yang dilakukan secara spontan dan penuh sukarela tanpa ada paksaan. 3). Bermain bersifat insidental sehingga dalam bermain ada aturan yang diciptakan oleh pemainnya sendiri. 4). Anak bisa termotivasi untuk menyenangi permainan.

Masih dalam (Setiani, 2013) (Suyadi, 2010 : 68) mengatakan gerak motorik kasar adalah gerak anggota badan secara kasar atau keras. Menurut Suyadi (2010: 69) Hingga usia 5-6 tahun anak sudah dapat melakukan gerakan secara serentak pada waktu yang bersamaan dengan mengkombinasikan secara terorganisir semua bagian tubuhnya. Kemampuan gerak secara simultan telah lengkap dikuasai dengan kecepatan yang cukup serta daya tahan tubuh yang baik, anak dapat memainkan peran dalam kehidupan pribadinya hingga akhir pra sekolah.

Perkembangan fisik-motorik yang bisa dilihat pada anak usia 5-6 tahun, pada aspek motorik kasar bisa dilihat dari delapan indikator, menurut (Sulaiman et al., 2019) yaitu (1) dapat melakukan aktivitas naik turun tangga; (2) dapat melompat; (3) dapat berlari; (4) dapat melakukan aktivitas tubuh secara terkoordinasi untuk melatih kelenturan, keseimbangan, dan kelincahan; (5) dapat melakukan gerakan secara bersama tangankepala, mata-kaki-dalam gerakan tarian atau senam; (6) melakukan permainan fisik dengan aturan; (7) sudah terampil menggunakan tangan kanan dan kiri; (8) dapat melakukan kegiatan kebersihan diri. Dalam (Yohana Selvia Roni, Purwanti, n.d.) menurut K. Elieen Allen dan Lynn R. Marotz, (2010:149-150). Perkembangan gerak lokomotor anak usia 5-6 tahun yaitu, melompat dengan satu kaki, berjalan jinjit selama 20 detik, meloncat atau maju 10 kali berturut-turut tanpa terjatuh, berlari sepanjang 2 meter dengan atau tanpa rintangan.

Dalam (Setiani, 2013) menurut Slamet Suyanto (2003 : 54-56) mengatakan ada beberapa pola umum perkembangan motorik pada anak yaitu: a). Memiliki tahapan yang 
sama (Uniform Sequence), anak walau berbeda dalam mencapai kecepatan tetapi anak memiliki tahapan dan pola yang sama. b). Bersifat terus menerus atau kontinyu, di mulai dari yang sederhana menuju ke bagian yang sulit atau kompleks. c). Bersifat Proximo Distal, yaitu perkembangan yang terjadi di mulai dari bagian yang dekat dengan sumbu tubuh (tulang belakang). d). Bagian kepala mengalami perkembangan lebih dahulu di banding bagian yang lainnya (Chepalocoudal Direction). e). Umum ke khusus, memulai kegiatan dari yang bersifat umum ke kegiatan yang bersifat khusus (dari reflek bawaan ke arah gerak terkoordinasi). f). Kematangan, perkembangan yang sesuai dengan usia dan perkembangan sel syaraf.

Pada artikel (Addriana Bulu Baan, Hendriana Sri Rejeki, 2020) yang dimaksud dengan motorik kasar menurut (Samsudin, 2008) adalah semua kegiatan yang melibatkan otot-otot besar, meliputi gerak dasar lokomotor yaitu kemampuan melakukan gerakan tubuh untuk memindahkan tubuh dari satu tempat ketempat lain, non lokomotor yaitu gerakan tubuh yang tidak menyebabkan seluruh tubuh berubah tempat dan manipulatif yaitu kegiatan yang biasanya menggunakan tangan dan kaki yang bersifat reseptif dan propulsif, menerima suatu objek dan mengerahkan kekuatan untuk suatu objek. Gerakan motorik kasar merupakan bagian dari kegiatan yang meliputi keterampilan otot-otot besar, dengan mengutamakan keseimbangan dan kekuatan fisik.

Dan menurut (Desmita, 2013) Keterampilan motorik kasar (gross motor skill), meliputi keterampilan otot-otot besar lengan, kaki, dan batang tubuh, seperti berjalan dan melompat. Masih menurut (Samsudin, 2008) dalam pengembangan motorik kasar bagi anak usia dini bertujuan untuk memperkenalkan gerakan kasar, meningkatkan kemampuan mengelola, melatih gerakan kasar, koordinasi dan mengontrol gerakan, serta meningkatkan keterampilan dan cara hidup sehat.

\section{METODE}

Penelitian yang dilakukan oleh penulis menggunakan studi kasus pada seorang anak usia 5-6 tahun yang bermain sepeda roda dua dengan fokus pada melatih motorik kasar anak, yaitu dengan gerakan lokomotor, non lokomotor, serta gerakan manipulatif. Adapun tahapan yang dilakukan dalam penelitian ini adalah dengan mengindentifikasi masalah pada anak selama pandemi covid-19, mencari landasan teori yang berhubungan dengan masalah yang akan di teliti, menentukan metode penelitian, menganalisis data dan membuat kesimpulan.

Menurut (Sugiono, 2008: 9) dalam (Yohanes Pambudi, 2013) Jenis penelitian studi kasus masuk sebagai salah satu jenis dalam metode penelitian kualitatif. Metode kualitatif adalah analisis data bersifat induktif dan hasil penelitian menekankan kepada makna, dimana peneliti sebagai instrumen kunci, teknik pengumpulan data dilakukan dengan triangulasi (gabungan), metode penelitian yang digunakan untuk meneliti kondisi obyek yang alamiah.

Dalam artikel (Zahroh \& Na'imah, 2020) menurut (Yusuf, 2014) Studi kasus digunakan untuk melihat secara utuh, lengkap dan mendalam mengenai suatu persoalan individu atau kelompok.

\section{HASIL DAN PEMBAHASAN Hasil}

Bermain sepeda merupakan kegiatan yang sangat menyenangkan bagi anak, karena anak dapat berinteraksi dengan lingkungan sekitar dan juga mendapatkan pengalaman dalam aktivitas bermain sepeda. Selain bermain, anak juga akan mendapat manfaat dari permainan yang dilakukan, misalnya anak menjadi sayang dengan barang yang dimilikinya, muncul keinginan untuk merawat dan juga menjaganya. Secara kemampuan fisik bermain sepeda bagi anak secara langsung juga telah melatih kemampuan motorik kasar dan juga motorik halusnya. Karena permainan ini mengandung unsur mengembangkan kemampuan lokomotor, non lokomotor dan juga gerakan manipulatif. Dalam bermain sepeda semua gerakan motorik kasar telah tercakup didalam bermain sepeda.

Gerakan-gerakan yang terjadi pada saat anak bermain sepeda secara langsung dapat dipilah, memudahkan untuk mengetahui gerakan apa saja yang telah dilakukan oleh anak ketika bersepeda. Pada hari pertama dan kedua hanya fokus pada gerakan lokomotor.

\section{Hari Pertama Dan Kedua Gerakan Lokomotor}

\begin{tabular}{|l|l}
\hline Aktivitas & Gerakan lokomotor \\
\hline
\end{tabular}


Mahkamah Brantasari. Jurnal Pendas Mahakam. Vol 5 (2). 119-125 Desember 2020

\begin{tabular}{|c|c|}
\hline Settingan & Bermain sepeda di halaman rumah \\
\hline Tugas & $\begin{array}{l}\text { Berjalan dan berlari } \\
\text { 1. Anak mengambil sepeda } \\
\text { 2. Menuntunnya dan kemudian } \\
\text { menaiki sepeda } \\
\text { 3. Mengembalikan sepeda } \\
\text { ketempatnya } \\
\text { Mengayuh } \\
\text { 1. Mengayuh pedal sepeda } \\
\text { 2. Mengerem sepeda atau } \\
\text { berhenti } \\
\text { Melompat } \\
\text { 1. Turun dari sepeda }\end{array}$ \\
\hline
\end{tabular}

Table 3.1

Pada hari ketiga dan keempat fokus pada gerakan non lokomotor. dan di ketahui banyak sekali gerakan non lokomotor yang dilakukan oleh anak.

\section{Hari Ketiga Dan Keempat Gerakan Non Lokomotor}

\begin{tabular}{|c|c|}
\hline Aktivitas & Gerakan non lokomotor \\
\hline Settingan & Bermain sepeda di halaman rumah \\
\hline Tugas & $\begin{array}{l}\text { Membungkuk } \\
\text { 1. Anak melakukan aktifitas } \\
\text { membungkuk Ketika duduk di } \\
\text { atas sadel sepeda. } \\
\text { Meregang atau peregangan } \\
\text { 1. Melakukan kegiatan } \\
\text { peregangan oleh anak ketika } \\
\text { anak merasa terkejut } \\
\text { Memutar } \\
\text { 1. Anak melakukan kegiatan } \\
\text { memutar saat mengendarai, di } \\
\text { atas sadel sepeda dapat } \\
\text { melakukan gerakan memutar } \\
\text { untuk melihat posisi belakang. } \\
\text { Mengayun } \\
\text { 1. Dalam proses mengendarai } \\
\text { sepeda tangan anak mengayun } \\
\text { karena salah satu tangan tidak } \\
\text { di gunakan untuk memegang } \\
\text { setir sepeda. } \\
\text { Mendarat }\end{array}$ \\
\hline
\end{tabular}

1. Turun dari sadel sepedanya, baik dengan kedua kaki maupun dengan satu kaki. Gerakan ini di lakukan berulang-ulang kali.

Berhenti

1. Prosesi mengerem yang sering dilakukan ketika anak bermain sepeda.

Mengelak

1. Mengelak dilakukan anak ketika menghindari sesuatu yang ada di jalan dan anak membelokkan sepedanya untuk menghindari rintangan yang ada.

Keseimbangan

1. hal ini adalah proses yang pasti akan dilakukan anak dalam mengendarai sepeda, agar tidak terjatuh maka anak akan dengan sendirinya menyeimbangkan tubuh.

\section{Menggoyang}

1. Dalam bersepeda anak terkadang menggoyanggoyangkan tubuhnya diatas sepeda.

Mendorong,

1. anak mendorong sepeda sebelum naik di sadel sepeda. dan juga dilakukan saat anak turun dari sepedanya dan mendorong sepedanya untuk parkir.

Menyetir.

1. Anak dengan kedua tangan memegang setir, agar sepeda dapat berdiri seimbang dan berjalan lurus.

Berbelok,

1. kegiatan yang akan dilakukan anak ketika akan menikung atau berbalik arah, berbelok yang dilakukan anak dengan derajat yang berbeda sesuai dengan keadaan tertentu. 
Mahkamah Brantasari. Jurnal Pendas Mahakam. Vol 5 (2). 119-125 Desember 2020

Table 3.2 Manipulatif

Hari Kelima Dan Keenam Gerakan

\begin{tabular}{|l|l|}
\hline Aktivitas & Gerakan manipulatif \\
\hline Settingan & Bermain sepeda di halaman rumah \\
\hline Tugas & $\begin{array}{l}\text { Menendang dan menyepak, } \\
\text { gerakan yang dilakukan anak } \\
\text { setelah turun dari sepeda untuk } \\
\text { menyingkirkan penghalang dalam } \\
\text { kegiatan bersepeda. }\end{array}$ \\
\hline
\end{tabular}

Table 3.3

\section{Pembahasan}

Sesuai dengan tumbuh kembang motorik kasar anak usia 5-6 tahun, maka yang harus diperhatikan adalah unsur gerakan yang ada pada motorik kasar itu pada saat bermain sepeda, yaitu:

a) Gerakan lokomotor itu sendiri dapat di lihat pada saat anak bersepeda, ada gerakan yang menyebabkan anak memindahkan tubuh dari satu tempat ketempat lain, hal ini dilakukan anak dengan cara:

1. Berjalan, merupakan proses menggerakkan kaki secara bergantian antara kaki kanan dan kaki kiri, lengan dan kaki bergerak secara berlawanan. Dalam proses berjalan, ketika salah satu kaki diayunkan untuk melangkah maka satu kaki yang lain akan tetap bertahan menginjak tanah. Aktivitas ini akan terlihat pada saat anak memulai bersepada, menuntun sepeda, turun dari sepeda dan menyandarkan sepedanya.

2. Berlari, kegiatan yang prosesnya sama dengan berjalan akan tetapi dilakukan dengan cepat, ada aktivitas berlari yang dilakukan ketika anak menuntun sepedanya.

3. Melompat, kegiatan ini sering sekali dilakukan anak ketika akan turun dari sepeda yang dikendarainya.

4. Mengayuh, sepeda yang dikendarai anak agar dapat berjalan atau bergerak maka anak mengayuh pedal sepeda agar sepeda dapat bergerak maju. Apabila kaki kanan mengayuh pedal kedepan maka kaki kiri posisinya berada dibelakang.
Dari kegiatan lokomotor yang diamati dan diberikan penilaian diketahui bahwa bermain sepeda dapat di gunakan untuk melatih kemampuan motorik kasar anak karena semua hal yang berhubungan dengan kegiatan lokomotor dilakukan anak dengan baik dan sempurna, hal yang dapat dijadikan kriteria keberhasilan itu sendiri berdasarkan pada apa yang anak telah lakukan yaitu aktivitas berjalan, berlari, melompat dan mengayuh dalam prosesi kegiatan lokomotor terlaksana dengan baik. Dalam artikel (Agustini, Tomi, \& Sudjana, 2016) gerak berjalan menurut FKKG (Forum Kelompok Kerja Guru) PJOK (2010:3) adalah telapak kaki yang menempel sempurna pada lantai, pandangan lurus mengarah ke depan, kedua tangan lurus disamping badan dan ayunan tangan santai.

Masih dalam artikel (Agustini et al., 2016) menurut Tomo (2012:15) gerak lari adalah aktivitas mengangkat kaki mengarah kedepan dan dihentakkan dengan kuat, gerakan kaki dan lengan mengayun berlawanan, gerakan lengan dekat dengan badan dan ayunan lengan membentuk sudut 90 derajat, gerakan kaki dan lengan harus santai sesuai dengan irama hentakan kaki. Menurut Edy (2010:22) melompat adalah mengangkat tubuh dengan dua buah kaki yang kemudian mendarat dengan dua kaki, melompat tanpa awalan dengan tolakan dua kaki mendatar mempunyai langkahlangkah sebagai berikut, dimulai dengan berdiri pada sikap jongkok dan ujung kaki jinjit, lalu tangan diayun kedepan mengikuti tolakan kedua kaki. Lakukan gerakan mendarat dengan kedua kaki bersamaan dan kedua lutut mengeper.

b) Gerakan non lokomotor dapat di lihat pada aktivitas:

1. Membungkuk, ada banyak dalam kegiatan bersepeda yang menyebabkan anak melakukan gerakan membungkuk, pada saat anak berada di atas sadel dan mengendarai sepeda atau ketika anak sedang melihat ban sepedanya.

2. Meregang atau peregangan terjadi ketika mengendarai sepeda anak bisa menjadi terkejut sebab menabrak batu di jalan sehingga gerakan meregang pada wajah anak tampak,

3. Memutar, saat mengendarai sepeda anak juga sering melakukan kegiatan memutar, anak yang duduk di atas sadel 
sepeda dapat melakukan gerakan memutar untuk melihat posisi belakang.

4. Mengayun, dalam proses mengendarai sepeda tangan anak bisa mengayun karena salah satu tangan tidak di gunakan untuk memegang setir sepeda.

5. Mendarat, kegiatan yang dilakukan anak ketika turun dari sadel sepedanya, baik dengan kedua kaki maupun dengan satu kaki.

6. Berhenti, prosesi yang sering dilakukan ketika anak bermain sepeda.

7. Mengelak, dalam kegiatan bersepada mengelak dilakukan anak ketika menghindari sesuatu yang ada di jalan dan anak membelokkan sepedanya untuk menghindari rintangan yang ada.

8. Keseimbangan, hal ini adalah proses yang pasti akan dilakukan anak dalam mengendarai sepeda, agar tidak terjatuh maka anak akan dengan sendirinya menyeimbangkan tubuh.

9. Menggoyang, dalam bersepeda anak terkadang menggoyang-goyangkan tubuhnya diatas sepeda.

10. Mendorong, aktivitas yang dilakukan pada saat akan memulai bermain sepeda, anak mendorong sepeda sebelum naik di sadel sepeda. Dan juga dilakukan saat anak turun dari sepedanya dan mendorong sepedanya untuk parkir.

11. Menyetir. Anak dengan kedua tangan memegang setir, agar sepeda dapat berdiri seimbang dan berjalan lurus.

12. Berbelok, kegiatan yang akan dilakukan anak ketika akan menikung atau berbalik arah, berbelok yang dilakukan anak dengan derajat yang berbeda sesuai dengan keadaan tertentu.

Demikian juga halnya gerakan non lokomotor, dalam bermain sepeda anak juga melakukan aktivitas yang ada unsur gerakan non lokomotornya, dalam artikel (Hidayat, 2017) menurut (Sukintaka, 1992) gerak non lokomotor adalah gerakan yang dilakukan di tempat (tidak menyebabkan berpindah tempat).

Kemampuan non lokomotor terdiri dari menekuk dan meregang, mengangkat dan menurunkan, melipat dan memutar, mendorong dan menarik, melingkar, mengocok, melambungkan dan lain-lain. Dan menurut
(Saputra ,2000). Contoh gerak non lokomotor adalah: menekuk, mengayun, mengulur, bergoyang, mendorong, berbelok, berputar, meliuk, mengangkat dan mendarat.

c) Gerakan Manipulatif,

1. Menendang dan menyepak, gerakan yang dilakukan anak setelah turun dari sepeda untuk menyingkirkan penghalang dalam kegiatan bersepeda.

Gerakan manipulatif masih dalam (Hidayat, 2017) menurut (Saputra, 2000) adalah gerakan-gerakan yang dapat dikembangkan pada saat anak telah menguasai berbagai objek. Kemampuan manipulatif lebih banyak menggunakan bagian tubuh terutama yang melibatkan tangan dan kaki. Bentuk-bentuk gerak manipulatif terdiri dari gerakan menerima (menangkap), gerakan mendorong (melempar, memukul, menendang) dan gerakan memantulmantulkan bola atau menggiring bola.

Pada artikel (Jhony \& Putra, 2019) Menurut Sujiono (2007:124) mengatakan bahwa gerakan manipulatif adalah kegiatan yang dilakukan oleh tubuh dengan bantuan alat. Sedangkan menurut Suyantini (2013:3) masih dalam artikel (Jhony \& Putra, 2019) gerak manipulatif merupakan gerakan yang memerlukan keterampilan dan koordinasi dengan ruang dan benda yang ada di sekitarnya atau kegiatan yang dilakukan tubuh dengan bantuan alat.

Dari apa yang telah dilakukan pada saat aktivitas bermain sepeda maka semua gerakangerakan yang dilakukan anak pada saat bermain sepeda, semuanya telah mengacu pada kemampuan motorik kasar anak, terutama anak usia 5-6 tahun.

\section{SIMPULAN}

Anak pada usia dini sangat penting untuk melakukan gerakan fisik dengan tujuan untuk merangsang pertumbuhan fisik motorik anak, baik motorik halus maupun kasar. Pada masa Pandemi Covid-19 dimana semua orang, baik orang dewasa hingga anak-anak dianjurkan untuk tidak berkegiatan di luar rumah, khususnya kegiatan yang bersifat keramaian, maka dari itu bermain sepeda dapat dilakukan di halaman rumah, atau daerah lapang yang memiliki sedikit pengunjung dengan tetap memenuhi standar protokoler. Aktivitas bermain sepeda dilakukan untuk 
menyeimbangkan kegiatan anak dan juga sekaligus melatih motorik kasar anak khususnya anak usia 5-6 tahun.

Gerakan-gerakan yang ada pada bermain sepeda sudah memenuhi standar gerakan motorik kasar yang terbagi pada tiga unsur gerak yaitu gerak lokomotor, non lokomotor serta gerakan manpulatif. Ketiga unsur gerakan akan lakukan anak ketika anak sudah dapat dengan sempurna melakukan kegiatan berjalan, merangkak dan berlari yaitu kegiatan yang berhubungan dengan motorik kasar, dengan tidak mengesampingkan perkembangan motorik halusnya, anak yang perkembangan motoriknya sudah sempurna akan lebih mudah melakukan kegiatan bermain sepeda, karena berhubungan dengan kegiatan penyeimbangan tubuh, serta mengayuh sepeda dengan baik.

\section{DAFTAR PUSTAKA}

Addriana Bulu Baan, Hendriana Sri Rejeki, N. (2020). Perkembangan Motorik Kasar Anak Usia Dini. Bungamputi, 6(0), 1421.

Agustini, I. P., Tomi, A., \& Sudjana, I. N. (2016). Metode Bermain Dalam Pembelajaran Pendidikan Jasmani Siswa Kelas III C SDN Krian III Kabupaten Sidoarjo. Pendidikan Jasmani, 26(2), 229-237.

Hasanah, U. (2016). Pengembangan Kemampuan Fisik Motorik Melalui Permainan Tradisional Bagi Anak Usia Dini. Pengembangan Kemampuan Fisik Motorik Melalui Permainan Tradisional Bagi Anak Usia Dini, 5(1), 115-134. https://doi.org/10.21831/jpa.v5i1.12368

Hidayat, A. (2017). Peningkatan Aktivitas Gerak Lokomotor, Nonlokomotor Dan Manipulatif Menggunakan Model Permainan Pada Siswa Sekolah Dasar. Jurnal Pendidikan Jasmani Dan Olahraga, 2(2), 21. https://doi.org/10.17509/jpjo.v2i2.8175 Jhony, H., \& Putra, G. I. (2019).
Mengembangkan Keterampilan Gerak Dasar Manipulatif bagi Anak Melalui Permainan Olahraga di Taman KanakKanak. Jurnal Muara Pendidikan, 4(2), 438-444. Retrieved from https://journal.unnes.ac.id/nju/index.php/ miki/article/download/8739/6697

Setiani, R. E. (2013). Memahami Pola Perkembangan Motorik Pada Anak Usia Dini. INSANIA : Jurnal Pemikiran Alternatif Kependidikan, 18(3), 455-470. https://doi.org/10.24090/insania.v18i3.14 72

Sulaiman, U., Ardianti, N., Pendidikan, J., Anak, I., Dini, U., Pendidikan, J., ... Pendidikan, S. N. (2019). Tingkat Pencapaian Aspek Perkembangan Anak Usia 5-6 Tahun. NANAEKE Indonesian Journal of Early Childhood Education, 2, 52-65.

Sutini, A. (2018). Meningkatkan Keterampilan Motorik Anak Usia Dini Melalui Permainan Tradisional. Cakrawala Dini: Jurnal Pendidikan Anak Usia Dini, 4(2), 67-77. https://doi.org/10.17509/cd.v4i2.10386

Yohana Selvia Roni, Purwanti, D. M. (n.d.). UPAYA MENINGKATKAN GERAK LOKOMOTOR MELALUI PERMAINAN ATRAKTIF DAN KOMPETITIF PADA ANAK USIA 5-6 TAHUN. 1-12.

Yohanes Pambudi. (2013). STUDI KASUS IMPLEMENTASI PENDIDIKAN KARAKTER MELALUI KULTUR SEKOLAH DI SMK NEGERI 2 DEPOK SLEMAN.

Zahroh, S., \& Na'imah, N. (2020). Peran Lingkungan Sosial terhadap Pembentukan Karakter Anak Usia Dini di Jogja Green School. Jurnal PG-PAUD Trunojoyo: Jurnal Pendidikan Dan Pembelajaran Anak Usia Dini, 7(1), 1-9. https://doi.org/10.21107/pgpaudtrunojoyo .$v 7 i 1.6293$ 